\title{
XII.-Comparative Therapeutics.'
}

Perhaps nothing could afford better evidence of the progress of modern veterinary science than the success which has attended the efforts to establish a rational system of medication for the cure of the diseases to which the domesticated animals are liable. It is true that the attempts to place veterinary therapeutics on a scientific basis date but a few years back-only, indeed, since the anatomy and physiology of these animals has been carefully studied, and the aid of chemistry and botany have been invoked; but recent though these attempts have been, it is none the less a fact that the progress made in this direction has been most creditable, and marks a distinct epoch in the history of veterinary science. It appears but a short time since the practice of medicine was something even less than empirical, and consisted in administering drugs whose properties were unknown, for the cure of diseases which were not understood. The chief thing then arrived at seems to have been to put a great number of ingredients together, each of which was supposed to possess some peculiar property, so that the combination should produce as many effects as there were medicines. No regard was paid to incompatibility, either in a physiological or chemical sense, and the specific action of any particular agent was never thought of. And not much more than a century ago the remedies prescribed were even more objectionable; for it appears as if no potion could possess any virtue unless the most filthy matters were incorporated with it; and we read of hedgehogs put into a covered pot and stewed alive, to furnish medicine for a cough, or a living fowl ripped open and applied to a sprained tendon. To their honour be it said, members of the medical profession were the first to rescue veterinary medicine from the degraded hands of the farrier, and to Doctors Gibson and Bracken, who lived in the middle of the last century, we owe the first attempts towards treating the diseases of animals in a reasonable manner. So low does veterinary medicine seem to have been at that time, that those physicians who began to study and write concerning it offer frequent apologies to their brethren for so debasing themselves. Thus, Bracken, in the preface to the seventh edition of his 'Farriery Improved'

1 1. Veterinary Medicines, their Actions and Uses. By FinLar Dun, formerly Lecturer on Materia Medica and Dietetics at the Edinburgh Veterinary College. Fourth Edition. Edinburgh, 1874. Pp. 576.

2. The Specific Action of Drugs on the Healthy System; an Index to their Therapeutic Value, as deduced from Experiments on Man and Animals. By Alexander G. Bunness, M.B., C.M. Univ. Aberd., and F. J. Mavor, M.R.C.V.S., President of Central Veterinary Society. London, 1874. Pp. 184. 
(published in 1752), speaking of the theory of medicine, writes :

"A human body is a curious machine, and so is that of every creature through the whole creation, for the component and constituent parts of a horse are subject to the same laws of motion as those of a human body, and both these to the same laws by which the infinitely wise God governs the universe. For both man and beasts are composed of solids and fluids, which are governed by the laws of gravitation, impulse, and reaction, and what changes are brought about in the animal economy by the motion of matter, under the conduct of those laws, can no way be estimated so well as from the mathematics.

"Let us not wonder, then, to see a physician take pen in hand in order to write down a discourse upon the distempers in horses, seeing (as I have said before) the property of body is alike in human and brute creatures. And, besides, there is full as much learning required to treat tolerably upon this subject as there is in compiling any other physical treatise, which trath I could plainly make appear from several circumstances, but that my time at present forbids it. Therefore, I say, let not my brethren murmur and complain at me, as if $I$ were debasing the profession, seeing it is certainly a fact that he who cannot write sensibly about the distempers in brute creatures is not fitly qualified to prescribe for man, by reason, 'tis plain, he has not studied nature thoroughly."

And referring to the silly nostrums for which every empiric had his own recipe, he says:

"I must likewise inform the reader that I had the offer of numberless receipts (as they are termed) from several gentlemen, that I might insert them in this book, but I have not in the least made use of any of them, seeing he who has his head full of receipts has his head full of nonsense, by reason that there is not any such thing as practising by receipts, and a number of them only serve to perplex and confound the reader. Therefore $I$ have not erred in this particular, although I hope I have set down what is necessary for the cure of each distemper in horses."

The change thus begun was continued, but made slow progress. The Brackens and the Gibsons were few and far between, and the farriers proved too strong for them until within the memory of the present generation, when men of education became veterinary surgeons, and, adopting every scientific discovery that might assist them, and especially in physiology, veterinary materia medica and therapeutics were carefully and systematically studied.

The results of this study are now before us in Mr. Finlay Dun's excellent work on 'Veterinary Medicines, their Actions and Uses,' of which it is not too much to say that it is by far are best book on the subject in any language. For many years 
we were obliged, personally, to have recourse to the first-rate 'Praktische Arzneimittellehre für Thieraërtze,' by Hertwig, of the Berlin Veterinary School, and the as useful ' Nouveau Traité de Matière Médicale, de Thérapeutique, et de Pharmacie Vétérinaire' of Tabourin, of the Lyons Veterinary School. Indeed, until the appearance of Mr. Dun's work it may be said that we had no scientific treatise on the subject; and even the first edition, published in 1854, when he was a lecturer at the Edinburgh Veterinary School, though highly praiseworthy, was still not equal to the text-books of Hertwig and Tabourin. Now, however, in this, the fourth edition, we can confidently and honestly assert that the great improvements made in the intermediate editions have culminated in giving the medical man and veterinary surgeon the best work to be found on the subject of which it treats.

And this subject must ever prove, not only interesting, but of the highest importance to the physician, pharmacologist, and toxicologist, as well as to the veterinarian, as for many years the action of drugs and poisons on the lower animals has been the only safe guide in ascertaining their probable effect on man, and nearly every new medicine which has been added to the Pharmacopœia has been first tested in this way. Not only is the subject interesting and valuable from this point of view, but the differences in the physiological action of many substances in various species of animals is curious and noteworthy, particularly to the experimenter, who, if not aware of these, may arrive at erroneous conclusions with regard to the action of the same drugs on man. Some creatures can live, and even thrive, on vegetable substances which are a positive and active poison to others. Rabbits can eat belladonna, stramonium, and henbane with impunity, it is said; pigeons can revel on the poppy, and goats can enjoy masticating a quantity of tobacco which would produce serious effects on larger animals. Schweinfurth, in his splendid work on 'The Heart of Africa,' informs us that the long flower-stalks of the Nubian Dracana, or "dragon trees," serve as excellent food for camels in June, while for goats they are almost poison. It is the same with medicinal substances. For instance, as Mr. Dun points out, a few grains of tartar emetic cause almost immediate vomiting in dogs, whereas the same medicine, even when given in doses of several ounces, has scarcely any physiological effect on horses and cattle. Aloes, the most uniform and convenient purgative for horses, is uncertain and irregular in its action on cattle; and to purge dogs a dose of about a drachm, or eight times as much as is given to a man, is needed. He also correctly observes that opium, strychnine and ether, further afford good illustrations of 
the different effects which the same medicine has on various classes of animals; acknowledging, however, that in the present state of our knowledge we cannot satisfactorily account for some of the anomalies, though most of them depend on differences of organization and habit. Thus, in the horse, although the stomach is small, the intestines are capacious, highly vascular, and abundantly supplied with nerves; provisions which, while they ensure the thorough absorption of nutriment from bulky and comparatively innutritious food, render the animal peculiarly liable to super-purgation and inflammation of the bowels. Vegetable purgatives appear more suitable than mineral ones, and act chiefly on the large intestines, and only slightly on the stomach and small intestines. Except in disease, and under the influence of aconite and a few other poisons, horses never vomit, vomiting being hindered by the smallness of the stomach, by its distance from the diaphragm and abdominal muscles, and the consequent difficulty with which it can be compressed between the two; the strong ring of muscular fibres surrounding its œsophageal opening also, in all probability, operates powerfully in preventing regurgitation of the contents, and some authorities are even of opinion that the inaptitude of the vagus nerve to receive and convey the special irritation has something to do with the inability of solipeds to vomit. With regard to most substances which act as emetics for men and dogs, it is supposed that they produce a sedative effect when given to the horse in sufficient doses; but the author observes that the many sedatives available in human and canine practice operate uncertainly and imperfectly in horses, for which aconite is the only reliable sedative medicine. It is the same with sudorifics, which are less active and useful than in man, and are very apt to act on the kidneys, unless the animal be well clothed. Opium and other narcotics also exert less soporific influence on horses, and, indeed, on all the lower animals, than on man. We have given two, three, and even four drachms of gum opium, and three and four ounces of the tincture, without producing any very obvious effects.

With cattle we observe the same peculiarities in the action of medicines, and the majority of these may likewise be referred to the construction of their alimentary canal, and their lymphatic or phlegmatic temperament. In the Ruminantia, the stomach is quadrisected and extensively lined with insensible cuticular membrane, the first three compartments being much less vascular and more mechanical in their action than in that of man, the horse, or the dog. The first and third of these compartments always contain food, often in large quantity, and these facts, as Mr. Dun says, explain why cattle require such large doses of all 
medicines, why considerable quantities of irritant and corrosive poisons can be given them with comparative impunity, and why purgatives, unless in large doses and in solution, are so tardy and uncertain in their effects. The kidneys and skin of cattle are less easily acted upon than the corresponding organs in the horse, while their dull phlegmatic disposition resists the influence of tonics and stimulants to a wonderful degree.

The notion is very prevalent that medicines, when poured very slowly down a cow's throat-for medicines should always be given in a fluid form to ruminants-pass, like the ruminated food, direct to the fourth compartment, or true stomach. $\mathrm{Mr}$. Dun states, with regard to this notion: "From a number of observations made at the slaughter-houses on both cattle and sheep, I find that neither animal can be induced to exert this voluntary effort in behalf of our medicines, which, in all cases, no matter how slowly soever they may be given, fall into the first and second stomachs (compartments), whence they shortly pass onwards through the third and fourth stomachs, especially if given, as they always ought to be, with a large quantity of fluid." M. Colin, in his splendid work, "Traité de Physiologie comparée des Animaux domestiques,' has shown that experiments which consist in ascertaining immediately after death into what compartments the fluids which the animals had drunk have passed are not conclusive, as in a few minutes after being swallowed they pass from one reservoir to the other; while the violent movements of the animals during slaughter, the altered position, and the manipulations necessary to expose the stomach, completely alter what has happened immediately after deglutition. Having established a large fistulous opening in the rumen, towards the left flank of several bulls, he observed that when the animals drank, the food in this compartment was slightly elevated towards the upper part of the left hemisphere, and there quickly appeared a current of water between the right wall of the organ and the alimentary mass ; this stream, more and more marked, gradually rose until it covered the food. An instant afterwards, in consequence of movements impressed on the mass contained in the paunch, the water was mixed with the food. To discover how the fluid reached the viscus, Colin inserted his hand as far as the cardiac orifice, and he then found that when the animal drank from a bucket the waves (or gluts) were thrown with considerable force, and at regular intervals, into the first and second compartments, the insertion of the œsophagus being at the junction of these reservoirs. The second compartment (reticulum) was soon filled, and the water overflowing the fold which separates it from the first compartment flowed abundantly into that. Lastly, the finger placed in 
contact with the slightly closed lips of the œesophageal groove felt a very small quantity of water flowing directly into the third and fourth compartments. In addition, the energetic contractions of the reticulum, occurring at variable intervals, propelled a certain portion of its contents into the first and third compartments. The gluts or swallows of water ingested are so great when the animal drinks freely, that fifteen or sixteen are sufficient to send ten litres ( 2 gallons 1 quart) into the stomach. They are smaller if the water is poured slowly into the mouth, six to eight going to the litre, the greater part of which passes into the reticulum.

In this respect the result of Colin's experiments coincide with those obtained by Flourens ('Mémoires d' Anatomie et de Physiologie comparée,' p. 36), and prove that the water drank by an ox flows for the greater part into the first two compartments, whence it escapes partially into the third and fourth receptacles, the œsophageal furrow only conveying a very small quantity.

Stating that medicines generally operate on dogs much in the same way as on man, Mr. Dun nevertheless admits that there are some remarkable exceptions. For instance, dogs will take six or eight times the dose of aloes usually given to the human subject, but are seriously injured by half as much calomel or oil of turpentine as is prescribed for man. "And it is judiciously remarked that the opinion generally held, that medicines may be given to dogs in the same doses as to man, cannot be safely entertained without a good many reservations. In dogs the alimentary canal is short and straight, and purgatives consequently act with greater rapidity than in other domesticated animals. Another peculiarity is the facility with which they can be made to vomit, vomiting being often naturally produced by their eating various sort of grasses, by their swallowing nauseous or unpalatable matters, or by their overloading the stomach. These facts have to be borne in mind by the experimenter as well as by the veterinarian.

In the $\operatorname{dog}$ the kidneys are excited with more difficulty than in horses and cattle, and diaphoresis can scarcely be said to occur at all, the skin not being adapted for cutaneous transpiration. Mr. Dun forgets to mention the extremely irritant effect produced by oil of turpentine when applied to the skin or injected into the anus of the dog. Such an application is sometimes resorted to by cruel people when they wish to drive away strange dogs, and house-painters have been known to "turpentine" dogs for their amusement, and to witness the unfortunate creatures writhe in convulsions produced by the pain. Such conduct deserves the severest reprobation. A dog so treated becomes perfectly furious; if not tied up it rushes about in the most 
frantic manner, howling and yelling, tearing up the ground until its claws are worn to the quick, dashing hither and thither, and attacking its own body with its teeth, or flying at any animals or persons in its track. The furious form of rabies is so closely simulated, that this turpentine mania has not-unfrequently been mistaken for the terrible disease. Of course, the odour of the turpentine is so marked that such an error in diagnosis should not be possible, but it is well to know of the similarity in the manifestations of the two conditions.

It is to be regretted that Mr. Dun says so little about the medication of pigs, and contents himself with stating " that the effects of medicines on them are somewhat similar to their action on men and dogs, but the practitioner is seldom required to prescribe for these animals." Now, it is a fact that the pig is a very important animal as a food producer, and is reared in immense numbers on the Continent of Europe, in America, and even in this country; and when we know that it is liable to several most fatal maladies, one or two of which, as the socalled "hog cholera," sometimes sweep off thousands of the porcine tribe and cause most serious loss, it is a pity that British veterinarians do not devote themselves to a careful study of the maladies to which this creature is liable, and to their curative treatment. This has been already done-and well done-in France by Pradal ('Traité des Maladies du Porc,' 1848) and Benion ('Traité de l'Elévage et des Maladies du Porc,' 1872), and in Germany by Carsten Harms and others. These diseases acquire increased interest from the fact that some of them are transmissible to the human species, as trichiniasis and the "leprosy" or "measles" (Cysticereus cellulosus), and anthrax in its various forms.

However this may be, it is worth remarking that medicines have much the same action upon pigs as upon the human species, and in like doses; indeed, there is the most painful similarity, not only in this respect, but also with regard to the analogy and course of several diseases. This may be due to a large extent, of course, to the fact that man and the pig are omnivorous, and are submitted to highly civilised influences.

The modifications in the action of medicines brought about by age and size, mode of exhibition, habit, idiosyncrasies, diseases, external circumstances, \&c., are briefly alluded to.

The mode of exhibition of medicines to animals is a serious subject with the veterinarian, and frequently demands an amount of intrepidity, skill, and tact, which are not required for the lord of creation. Without mentioning the elephant or camel, creatures which not seldom come under his care in India, and which are not alluded to by Mr. Dun, there are the long jaws 
and powerful grinding molars of the horse to be encountered, as well as its front feet on occasions; the dangerous horns of the cow, the sharp fangs of the dog, and the tearing claws of the cat. It has even happened that the veterinary surgeon has had to encounter the tender mercies of the tiger, lion, and bear, when these have required medicines in their menagerie ailments; but of course no text-book would include these untamed brutes in its list. The subcutaneous mode of exhibition is gradually being resorted to, and with animals it possesses more advantages than it does in mankind, the greatest of which is facility in administration. "In giving medicines by the mouth, comparatively large doses must be given to herbivorous creatures, and especially ruminants, as the stomach usually contains more or less food, which may alter their properties and hinder their speedy and complete absorption. By having recourse to subcutaneous injection there is rapidity, certainty, and directness of effect, as well as a saving in the quantity of the drug. Mr. Dun asserts that it proves especially useful in arresting or controlling the spasms of colic and chronic cough, the sharp twinges of rheumatism, inflammatory pains, such as those of enteritis and pleurisy, as well as the effects of poisons. He also adds the necessary caution that, with active agents, it is unwise, without careful trial, to use more than one fourth of the dose which would be given by the mouth. The drug is best dissolved in water or some other perfectly bland fluid. One or two ounces of solution is sufficient for one injection for horses or cattle, and proportionately smaller amounts for sheep and dogs. There is less risk than in the human subject of untoward effects, and the operation is performed in a similar manner. A fold of skin is taken up between the finger and thumb of the left hand; a suitable syringe is quietly inserted with the right hand; the point is carried about an inch underneath the skin, parallel with the surface; it is then slowly emptied, held for half a minute, cautiously withdrawn, and the finger pressed for a minute on its track. No plaster or dressing is required for the puncture.

We are cognisant of some very striking, and almost instantaneous recoveries from paralysis of the hinder extremities in horses by the subcutaneous injection of strychnine over the loins, when the same remedy given by the mouth has proved impotent.

We are sorry we cannot afford to give a more extended notice of this most interesting and valuable work, which it has given us great pleasure to peruse and study, for there is ample material for instruction in its pages. The most recent discoveries and inquiries appear to have received due attention in its revisal, though we now and again miss something which has appeared 
in the foreign literature of the last three or four years. The improved chemical nomenclature, as well as the new notation, has been introduced. Everything relating to the individual medicines is noticed, the points chiefly dwelt upon being their natural history, preparation, properties, and most common impurities and adulterations; their general action on the various domesticated animals, and their uses, doses, and medicinal forms. In the previous editions there was an appendix, comprising short notices of the nature, causes, symptoms, and treatment of the most common diseases of the domesticated animals. In the volume before us this has been judiciously omitted, and in its stead is an index of diseases, in which are set forth, under each disease, the appropriate remedies, arranged chiefly in the order of their value or of their application in the earlier and later stages of the disorder. This will prove far more useful to students than the appendix, though it may be less appreciated by those amateurs who love to dabble in animal doctoring, which is somewhat common, although even more unsuccessful than amateur man-doctoring. Of this an amusing instance occurred in our own experience not long ago. An officer in command of a battery of field artillery, who had been several years among horses, and therefore, it may be supposed, considered himself privileged to prescribe for their ailments, requested our assistance in a case which had very much baffled him, though he had anxiously studied it book in hand in the sick stable. On our arrival we were shown an animal whose original colour had been a light grey, almost white, but which was now a primrose yellow from the inunction of mustard paste over the whole of its body and neck, and which was evidently suffering a considerable amount of pain. The officer explained that the horse was found on the previous Monday morning, when the men went to the stables, "blowing" very hard and refusing its food; and visiting it soon after, he diagnosed congestion or inflammation of the lungs. As mustard was his sheet anchor, large quantities of that substance mixed with strong ammonia were rubbed into the skin covering the sides of the chest as well as the neck. When the restlessness occasioned by this extensive irritation had passed away no amelioration in the blowing could be perceived, so the mustard was repeated. Chancing to be in the stable when the horse attempted to micturate, it was noticed that these attempts were only partially successful, and that the hind legs could not be extended backwards in the customary way, owing, it was suspected, to something being the matter with its loins. Inflammation of the kidneys was then pronounced to be the disease, and, accordingly, the back was largely plastered over with the sinapism. Not long afterwards the horse began to 
stand uneasily and evince a dislike to lie down; enteritis was then apprehended, and the mustard liberally applied to the abdomen. The popular work on 'The Horse and its Diseases' had been studied in vain; for the cause of all the symptoms, or rather the disease, was simple lymphangitis of one hind limban affection accompanied by much pain and fever, but which is readily amenable to treatment.

Messrs. Burness and Mavor, in their work on 'The Specific Action of Drugs,' as it is designated on the title-page, and 'The Therapeutic Action of Drugs' on the cover, give us the results of a series of experiments conducted at various periods, in order to ascertain the true therapeutic value of each drug, by noting its physiological action on the healthy system. Mr. Burness has, it appears, devoted for some time special attention to this subject, with the object of treating diseases on some scientific principle, and not by empiric remedies; and as $\mathrm{Mr}$. Mavor held similar views to his own, and had also experimented extensively on the lower animals-Mr. Burness's observations being more particularly directed to the human species-the results obtained by both are conveniently classified under different headings. The purport of the work, as we are informed in the introduction, is-

"To point out that the full therapeutic value of each substance-its value in the treatment of disease-is only to be determined by ascertaining the symptoms produced, and the parts influenced by each substance when introduced into the healthy animal economy; and that this is to be done by careful observation of cases where a substance has been introduced either by accident or intention, the quantity taken in each case, as well as the form and mode in which introduced, being also noted."

The work is conveniently divided into chapters, in the first of which examples are given to show that each disease is characterised by certain primary symptoms peculiar to itself, and which are caused, in most cases, by some unknown agency that acts in a specific manner on some special parts or tracts ; and instances are also brought forward as evidence to prove that there are various known agents which primarily influence certain parts, and produce certain symptoms peculiar to each when introduced into the healthy body, this influence being due to their physical, chemical or dynamical properties.

The second chapter is designed to show that the knowledge of the specific action of each substance thus obtained is the key to its therapeutic value, allusion being also made to the fact that each substance exerts a twofold action upon the same part, according to the quantity taken and the state of the part-one, its physiological action, and another, which the authors, for lack 
of a better name, designate its " restorative" action. Indications are also afforded where it is advisable to employ an agent, either in physiological or in the so-called restorative doses. Illustrative cases are adduced to show that experience has already proved the correctness of the above assertions.

The third chapter deals with the form and mode of administering various substances for therapeutical purposes.

Chapter IV contains notes on temperature in health and disease, and the influence of various substances upon it. The remainder of the work is allotted to a consideration of the specific action of various drugs, as demonstrated by experiments conducted, when possible, on man and animals by the authors, and in other instances from reports of poisoning in treatises on toxicology, the therapeutic use of each drug being indicated in man and animals :

"For," say they, "we are convinced that when a certain drug influences special parts in the human body, it influences parallel parts in the animal body, both in the healthy and diseased state, although not necessarily producing in all cases the same train of symptoms; in fact, the diseases to which animals are subject are brought about in the same way as in man, viz. by some cause inducing primary derangement of some special parts or tracts, and that the same remedies which restore the functions of these parts or tracts in man will serve the same purpose in animals, in the majority of cases."

Their theory is founded on the fact that all non-nutritious agents, whether formed in the body or introduced accidentally or intentionally, tend to pass out by some one or other of the eliminating tracts, and in their passage affect these tracts by virtue of their physical, chemical, or dynamical properties; the word tract being preferred to organ, for the reason that no agent primarily influences any special organ as a whole, but only some special part of it, and from its influence over this it may affect the function of the whole organ.

Having given this summary of the work, it will be seen that it is really a treatise on the action and uses of medicines in man and the domesticated animals, and that its value must be estimated chiefly by the light it throws on the modus operandi, in health and disease, of the number of drugs the authors have experimented with. In this respect it must be admitted that the results of their labours have been most satisfactory; and while, in regard to several of the substances, we only receive confirmatory evidence of what was before pretty well known, we are furnished with interesting and novel facts pertaining to other drugs, which are also to be prized for their practical importance and utility. 
In the chapter on the mode of administering drugs we find the great value of the hypodermic method here also strongly insisted upon, especially in introducing into the system such medicaments as morphia, atropine, strychine, aconitina, quinine, ergot, \&c., as by it we can, with a comparatively small dose and in a short space of time, produce more or less of the physiological effects of the drug, and at the same time avoid the risk of deranging the digestive organs or having the property of the drug altered by the digestive fluids. In all acute diseases, especially if attended with pain, this method is to be preferred; in pleurisy, for instance, by the subcutaneous injection of morphia and atropine we can at once relieve the pain and in a short space of time subdue the disease, while in many other diseases pain can be removed by morphia thus administered, appropriate remedies being used at the same time to remove the cause of the disease.

"In the treatment of the diseases of animals this method of introducing remedial agents into the system is invaluable, and will, we are sure, eventually supersede the boluses and drenches, which are often so difficult to give, so difficult to take, and, in some cases, of so little good when taken. By this method the special agent is at once introduced into the circulating fluid, and in a short time comes in contact with, and acts upon, the part or parts over which it has specific influence. And although at present comparatively few drugs have been used in this way, we doubt not that more will be added to the list when we can prepare solutions of the active principles in such manner as they will not act as topical irritants."

It is incidentally mentioned that, in the human subject, ergotine may be used subcutaneously for internal hæmorrhages or purpura, when prepared as follows:

\section{Ergotine, grains 5;}

Glycerine, 1 drachm.

Twelve minims to be injected twice a day.

It is also noticed that in administering morphia in this way the sickness which is sometimes produced is obviated if a small proportion-about $\frac{1}{60}$ th of a grain- of atropine be given at the same time; and in those cases in which we wish to relieve pain, as in neuralgia, sciatica, \&c., without producing sleep, it is a good plan to give a small quantity for a dose, and repeat at intervals of six to nine hours if required- say about $\frac{1}{10}$ th of a grain of morphia with $\frac{1}{60}$ th of a grain of atropine.

"By this means we have the first dose eliminated from the system, to a great extent, before a second dose is given, and thus there is never sufficient in the system at one time to produce toxic effects. Of course, the effects of the first dose should be allowed fully to pass off before giving a second dose. In those cases in which we 
wish to produce sleep, it is the best plan to give a large dose at once, and thus obtain the physiological effect of the drug."

The hint is also given that the readiest antidote to strychnine is the hypodermic injection of morphia, and vice versâ. In an experiment on a dog, half a grain of acetate of morphia was given, and in two hours, when the full physiological effects of the drug were developed, $\frac{1}{16}$ th of a grain of strychnine was administered, and in forty minutes the dog had quite recovered. In another instance, a horse received $1 \frac{1}{4}$ grain of strychnine, which induced rigidity of the muscles and the other characteristic symptoms within an hour. Then ten grains of acetate of morphia were given, and in an hour and a half the animal was nearly well and quiet, and in three and a half hours it had entirely recovered. To another horse eight grains of morphia and one grain of strychnine were given at the same time, but no effect was produced except slight dilatation of the pupil.

The authors agree with what has been already stated as to the diminished quantity of a medicine sufficing when given subcutaneously, one half, or even a third, of the quantity of any drug required to produce a physiological effect being ample.

The notes on temperature in health and disease are alike instructive and useful, and the experiments resorted to are direct and indisputable in their results. The conclusion the authors drew from them was, that various non-nutritious agents introduced into the system in health, by producing deranged function, tend to raise the temperature; but when introduced into the system when the temperature is above the normal standard, tend to reduce it by restoring the deranged function and removing the disturbing cause, though it is shown that there are certain agents which have the power of reducing the temperature below the normal degree by their direct action on the blood.

In the case of a mare suffering from an abscess in the pectoral region, and whose temperature was $104 \frac{2}{5}^{\circ}$, three fourths of a grain of sulphate of atropine was given in quarter-grain doses in three days; with each dose the temperature fell, and after the third it gradually descended to about the normal standard. After each dose the pupils were dilated, and the mucous membrane of the mouth dry. Quinine also reduces abnormal temperature; so does digitalis and aconite, as shown by Wunderlich. $\mathrm{Mr}$. Mavor points out what we have frequently observed, that in horses affected with influenza, fever, \&c., the temperature is often $105^{\circ}$, and that half-drachm doses of tincture of aconite three times a day invariably succeed in reducing the temperature to the natural degree and cure the disease.

The experiments on horses are nearly all full of interest. Take 
the following two, with regard to hydrocyanic acid:-One drachm (fluid) of Scheele's prussic acid was injected subcutaneously ; no effect was observed until four hours after, when convulsive movements set in; the horse had great difficulty in standing, the pulse rose from 36 to 90 per minute, but it was small; the buccal mucous membrane was pale, and the ears cold and clammy; in a very short time these symptoms passed away, and the pulse fell to 48 per minute. In the second case half a drachm of prussic acid, containing 50 per cent. of anhydrous acid, was injected subcutaneously into a horse. In less than a minute it fell to the ground, striking out its limbs in a violent and convulsive manner, the respiration being difficult and spasmodic; within five minutes after the introduction of the prussic acid the animal was dead. After death the pupil was observed to be dilated and the eye glistening. The object in this case was to kill the animal as rapidly and painlessly as possible.

The experiments to test the physiological action of belladonna and its alkaloid atropia are also interesting and significant, as are also those to show the effect of this drug and morphia when admnistered together. The results of the latter experiments prove that morphia or opium rather tends to prolong and increase the effects of belladonna or atropia. Morphia given to an animal under the influence of the latter increases the distress and raises the pulse: on the other hand, it neutralises the effects of strychnine. Atropia in conjunction with strychnine has been used with great success in the treatment of tetanus in the horse, and it appears to prolong the action of the latter drug in these cases.

The therapeutic uses of nux vomica and strychnia are very fully illustrated, and with regard to the last it is mentioned that in the lower animals its subcutaneous injection more readily, more certainly, and in a shorter space of time, restores deranged function of the intestinal canal than any of the active purgative medicines which are commonly used in such cases.

With regard to the therapeutic action of bichromate of potash, it is important to remark that, in man, a full dose causes increase of the secretions of the mucous surfaces, the discharge being sometimes of a purulent character; also inflammation of the mucous membrane of the throat, great coryza, and hoarseness; cough and dyspnœa; frequently nausea; vomiting and dysenteric purging; papular eruptions on the skin, which assume a pustular character, and sometimes inflammation and ulceration of the nasal mucous membrane, with sneezing and fetid mucus discharge; the stools are sometimes rendered scanty and clay coloured, the urine purulent or totally suppressed, and the periosteum swollen and painful. Topically applied to the skin it acts as a caustic, often causes pustular sores, which slough, 106-IIII. 
and leave painful ulcers which are very difficult to heal. - In some cases it causes, by its topical action when swallowed, inflammation of the stomach, followed by vomiting, dyspnœa, paralysis, convulsions, and death.

To a horse at 12.25 midnight was given one drachm and a half of this drug, the temperature being $101 \frac{1}{5}^{\circ}$ and the pulse 36 . At $8 \mathrm{a} . \mathrm{m}$. the temperature was $104 \frac{1}{5}^{\circ}$ and pulse 40 ; at $12.20,104 \frac{2}{5}^{\circ}$ and pulse 40 ; at 1.15 the respirations were 20 ; the throat was much inflamed; there was coughing, the conjunctivæ were highly injected; there was a discharge of yellow mucus from the nostrils, and the tongue was very dry; the symptoms altogether resembling those of influenza; the temperature was $104_{4}^{3}$; pulse 40 .

Its use is stated by the authors to be indicated, among other diseases, in farcy and glanders, in the early stages of which they say it may be considered a specific and certain remedy; and in the number of cases illustrative of specific treatment in animals, we find one of a horse suffering from "farcy :"

"The nasal mucous membrane was ulcerated (!), the near hind limb much swollen, and the lymphatic vessels, both of this limb and other parts of the body, were much inflamed and ulcerated. This animal was treated with restorative doses of bichromate of potash and sulphide of potassium, given alternately. In a few ${ }^{\circ}$ days the ulceration of the nasal mucous membrane was healed, and the condition of the lymphatic system much improved. In a few weeks the animal was quite well and in good condition. This is but one of many successful cases so treated."

Now, from the knowledge we possess of this most formidable disease, we have every right to seriously question whether this was a cure; or, if it was, whether the disease was "farcy" (or glanders?)

In the first place, the ulceration of the Schneiderian membrane would designate it as "glanders," while the ulceration of the inflamed lymphatics would cause it to be pronounced glanders complicated with farcy-one of the most fatal and dangerous maladies to which the equine species is liable, and which, according to our experience and that of the most eminent Continental veterinary surgeons who have made it a life-study, is absolutely incurable. There is not a well-authenticated cure of glanders on record, and though cases of farcy are now and again recovered, yet they are only those in which the lungs are not involved, and the virus has been communicated locally; or they are spurious outbreaks, not the specific disease. Glanders has been apparently cured when in the chronic form, but it has only been apparently, for eventually the animals have succumbed to it. The lung infiltration, which is the earliest 
pathological alteration in glanders, may be checked for a time; but the horses are still capable of infecting, and may continue so for years until exposure to some exciting cause gives renewed vigour to the morbid process, when it reassumes the acute form. Such has been the experience of Haubner, Röll, Reynal, Bouley, and a host of the most trustworthy observers; and there is every reason to believe that if glanders could be cured, confirmed phthisis in mankind should be made readily amenable to remediable measures. Mistakes are frequently made in diagnosing both farcy and glanders: was it not so in the above instance? The description of the pathological appearances is so very meagre that no one could safely pronounce as to the disease; and until we have the fullest evidence that a horse suffering from the specific disease can be radically cured by administering the bichromate of potash and sulphide of potassium, we hesitate to give our credence to this recovery. There can be no difficulty in putting the virtues of these drugs to the test, however, as the malady is now, unfortunately, only too prevalent in and around London. We do not think there is on record a single case in which the disease, when transmitted to man, has been successfully treated. As in the horse species, it appears to be invariably fatal in him.

Notwithstanding our doubts as to the results obtained in this particular instance, we cannot allow them to detract from the high opinion we have formed of the labours of the authors of 'The Therapeutic Action of Drugs.' The volume is eminently practical and suggestive, and will be found of much value to the physician, toxicologist, and veterinary surgeon. It is very rare, indeed, to find a physician and veterinarian uniting in researches towards accomplishing the same object-the cure of disease in man and beast. The success of the present inquiry clearly demonstrates what valuable ends may be attained by such combined investigations, and how materially two such experimenters can assist each other, and advance the progress of science. We feel satisfied that we have performed a most useful work in bringing under our readers' notice two works of so much merit as those whose titles stand at the head of this article. 